\title{
A Guide to Collagen Sources, Applications and Current Advancements
}

\author{
Amrapali Sakpal ${ }^{\circledR}$, Sonal Patil ${ }^{\circledR}$, Smita Patil ${ }^{\circledR}$, Amol Date, Venkatesh Prasad, Santanu Dasgupta, \\ Bhaskar Bhadra* ${ }^{\circ}$
}

Synthetic Biology Group, Reliance Corporate Park, Reliance Industries Limited, Navi Mumbai-400701, India

E-mail: Bhaskar.Bhadra@ril.com

Received: 15 July 2021; Revised: 14 September 2021; Accepted: 5 October 2021

\begin{abstract}
The increase in use of collagen products in almost every sector of utility has stipulated the rising demand for collagen. It is an essential fibrous glycoprotein, which is abundantly present in the extracellular matrix and connective tissues in many living organisms. Owing to its unique characteristics such as biocompatibility, bioavailability and weak antigenicity it has gained major interest in the food, pharmaceutical, cosmetic, biomedical and leather industries. The collagen-based composites possess an enhanced capacity to dissipate mechanical energy, strength and stiffness making it the most promising biomolecule for its multifaceted applications. Recently, synthetic biology platforms are getting wide attention for the production of non-native collagen alternatives to meet the rising demand for collagen worldwide. In the initial part, this review aims to explain different sources, structures, biosynthesis of collagen and its types followed by the emerging applications of collagen as a next-generation biomaterial in the later part. The article emphasises the synthesis of non-native collagen using novel expression systems like plant and algae in addition to bacteria and yeast with industrial consideration. In the conclusion section, challenges and opportunities of using synthetic biology tools are described.
\end{abstract}

Keywords: collagen, drug delivery, cosmetics, nutraceutical, food industry, biomedical, gelatin, synthetic biology

\section{Research highlights:}

- The article reviews the structure, sources and types of native collagen with emphasis on opportunities and challenges in collagen application.

- The article attempts to introduce synthetic biology platforms and novel expression systems in combination with currently available techniques to encounter the current and projected escalated demand for collagen worldwide.

\section{Introduction}

Collagen is the most abundant structural protein in the animal kingdom constituting about $30 \%$ of the total protein content, especially in mammals. It is highly conserved across all the species. In invertebrates, it is present in the body wall and cuticles. It is absent in plants and unicellular organisms where polysaccharides and cellulose replace its function [1]. In mammals, it is involved in the formation of fibrillar and microfibrillar structures in the extracellular matrix (ECM) [2], which is a major component of connective tissues like bone [3], cartilage, tendons, etc. It is also present in blood vessels, the cornea [4], the dentin of teeth [5] and skin [6].

Copyright (C2021 Bhaskar Bhadra, et al

DOI: https://doi.org/10.37256/sbe. 1220211043

This is an open-access article distributed under a CC BY license

(Creative Commons Attribution 4.0 International License)

https://creativecommons.org/licenses/by/4.0/ 
The structural and signaling role of collagen makes it an ideal biomaterial for applications in the field of biomedical [7], cosmetics [8], nutraceuticals [9] and pharmaceuticals. In addition, natural properties like hemostatic activity [10], biodegradability [11] and cross-linking ability of collagen find a wide application in the drug delivery systems [12-14]. Gelatin, a biopolymer obtained by partial hydrolysis of collagen fibres has major applications in confectionery, food, pharmaceutical, medical, cosmetic products [15]. Gelatin derivatives such as Gelatin methacryloyl (GelMA) hydrogels are widely used for the construction of 3D scaffolds, injectable gels, bioprinted scaffolds, wound healing and biosensing [16]. In addition, the partial thermal hydrolysis of collagen polypeptides results in the formation of small peptides with a low molecular weight called hydrolyzed collagen (HC). These bioactive collagen peptides (BCP) have chemotactic properties in the bloodstream and help in the skin, hair restoration process [17]. The oral administration of these peptides has shown overall skin health improvement [18].

The majority of currently available collagen and collagen-based products are derived from marine and animal sources mainly from fish, bovine, porcine, etc.; however, considering the shortcomings like origin and acceptance of animal-derived collagen, foreignness, pathogenic contamination, etc. various alternatives like recombinant collagen is currently being explored [19]. For example, Fujifilm, Japan has developed a human type I collagen-based biomaterial under the commercial name Cellnest TM with enhanced cell adhesion capacity to be used in regenerative medicines like bone regeneration [20].

Different corporate sectors have explored the production of collagen from non-animal sources to meet the industrial demands using synthetic biology techniques. In the current review, we attempt to summarize the current advances in collagen production from different sources using novel expression systems like plants and algae with industrial consideration. Plant-derived collagen has been reported to be a safe alternative to allografts, animal collagen or recombinant collagen derived from yeast [21] with the advantage of the limitless supply. However, there is a scarcity of literature about the novel expression system for recombinant collagen production using such platforms. The information summarized in this review will help clinicians, researchers, and manufacturing companies not only to access the basic knowledge about sources, types, applications of collagen but also to portray the latest trends in collagen composites and synthetic collagen production.

\section{Structure of collagen}

Ramachandran and Karta originally described the structure of collagen in the Madras model [22]. According to this model, the collagen forms a right-handed triple helix of three alpha $(\alpha)$ polypeptide chains (Figure 1). Each chain exists in a left-handed polyproline type II helix forming a triple helical structure also called tropocollagen. All these three chains can be identical ( $\alpha_{1}$ chains called homotrimer) or unidentical ( $\alpha_{1}$ and $\alpha_{6}$ chains, called heterotrimer); the combination of $\alpha$ chains and the peptide sequence determines the type of collagen formed (Table 1) [23]. About 25 different $\alpha$ chain have been discovered which are involved in the formation of about 28 different types of collagen.

Each collagen triple helix is around $300 \mathrm{~nm}$ long and displays an unusual abundance of three amino acids: glycine, proline, and hydroxyproline [23]. These amino acids configure the characteristic repeating motif, Gly-X-Y, where X and $\mathrm{Y}$ are proline and hydroxyproline with glycine occupying the central axis. The side chain of glycine contains an $\mathrm{H}$ atom, which minimizes the steric hindrance within the alpha helices, which are held together by hydrogen bonds linking the -NH of a glycine residue with a carbonyl $(\mathrm{C}=\mathrm{O})$ group of glycine in an adjacent polypeptide.

The abundance of collagen in the animal kingdom is attributed to its unique characteristic of thermal and chemical stability which is contributed by both inter and intramolecular forces [24]. The stability to each left-handed $\alpha$ chain is imparted by interstrand hydrogen bonding while intrastrand $n \rightarrow \pi^{*}$ interactions stabilize the triple helix. The propyl-4hydroxylase and lysyl hydroxylase perform the hydroxylation of proline and lysine residues on the procollagen during posttranslational modification in the endoplasmic reticulum (ER) which further contributes to the stability and prevents the enzymatic degradation [25].

The non-collagenous domains further impart structural stability, and are usually found as the flanking regions on procollagen (-C and $-\mathrm{N}$ terminals). The cleavage of these termini forms the mature elongated collagen fibrils of about $1 \mathrm{~nm}$ to $1 \mu \mathrm{m}$ in diameter [25]. 


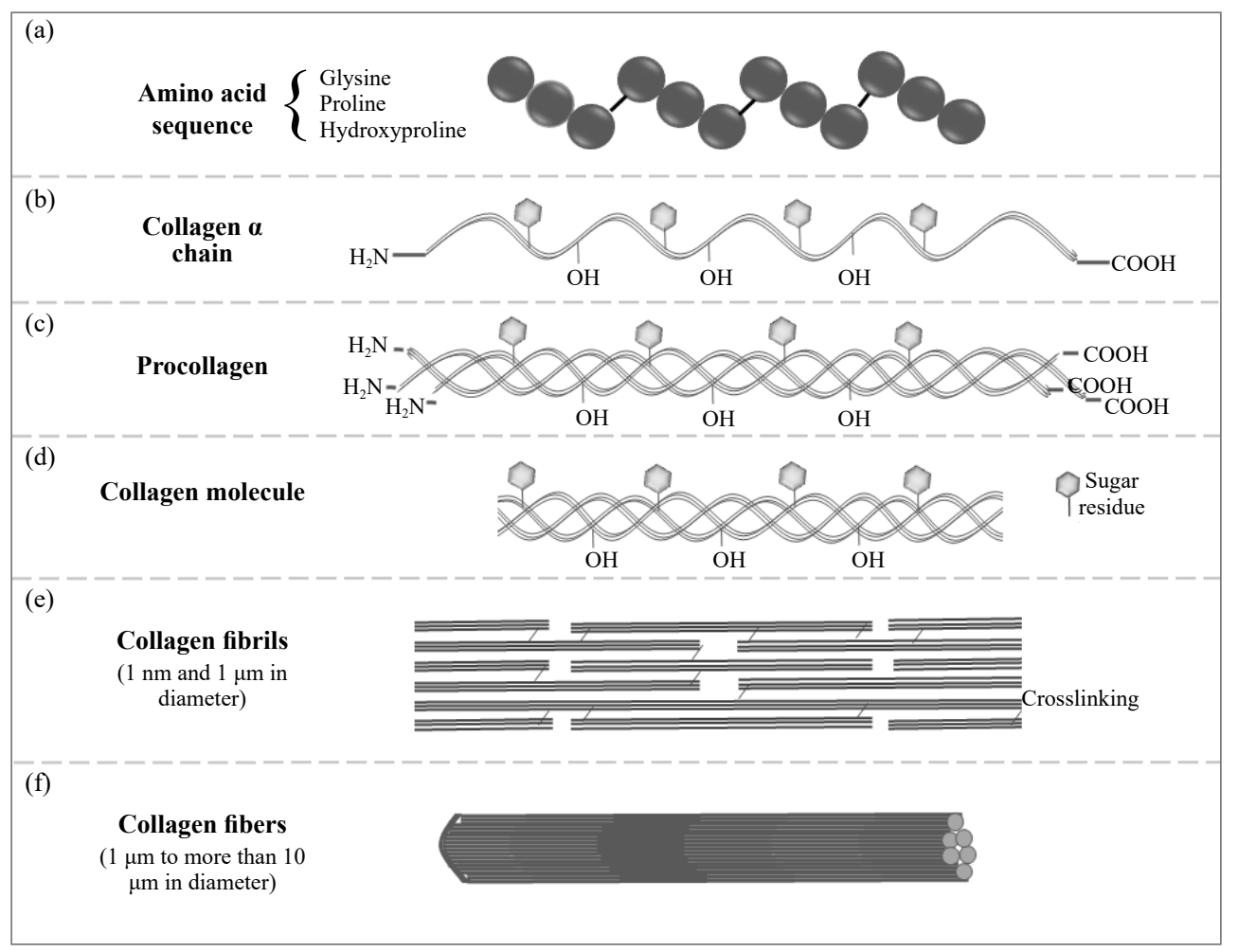

Figure 1. Molecular structure of collagen showing (a) organization of amino acids in $\alpha$ chain, (b) hydroxylated and glycosylated $\alpha$ chains, (c). triple helix of procollagen with amino and carboxyl termini, (d) a mature collagen molecule, (e) crosslinking of collagen molecules forming collagen fibrils and (f) supramolecular assembly of fibrillar collagen

Table 1. Types of collagen (I-XIV) and its composition of $\alpha$ chain

\begin{tabular}{cc}
\hline Type of collagen & Composition of $\alpha$ chains \\
\hline Type I & two $\alpha 1(\mathrm{I})$ chains and one $\alpha 2(\mathrm{I})$ chain \\
Type II & three identical $\alpha 1$ (II) \\
Type III & three identical $\alpha 1(\mathrm{III})$ \\
Type IV & two $\alpha 1(\mathrm{IV})$ chains and one $\alpha 2(\mathrm{IV})$ \\
Type V & $\alpha 1(\mathrm{VI}), \alpha 2(\mathrm{VI})$, and $\alpha 3(\mathrm{VI})$ \\
Type VI & three $\alpha 1(\mathrm{VII})$ \\
Type VII & two $\alpha 1(\mathrm{~V})$ chains and one $\alpha 2(\mathrm{~V})$ OR $\alpha 1(\mathrm{~V}), \alpha 2(\mathrm{~V})$, and $\alpha 3(\mathrm{~V})$ OR three of $\alpha 1(\mathrm{~V})$ \\
Type VIII & $\alpha 1(\mathrm{VIII})$ chains and one $\alpha 2(\mathrm{VIII})$ \\
Type IX & $22(\mathrm{IX})$, and $\alpha 3$ (IX) \\
Type X & homotrimeric compound of $\alpha 1(\mathrm{X})$ \\
Type XI & $\alpha 1(\mathrm{XI}), \alpha 2(\mathrm{XI})$, and $\alpha 3(\mathrm{XI})$ \\
Type XII & three $\alpha 1(\mathrm{XII})$ \\
Type XIII & - \\
Type XIV & three $\alpha 1(\mathrm{XIV})$ \\
\hline
\end{tabular}

Collagens molecules thus formed are deposited in the extracellular matrix (ECM) where most of them form supramolecular assemblies. They impart structural roles, contribute to the mechanical properties of the tissue organizations and maintains the shape of the tissue. 


\section{Biosynthesis of collagen}

\subsection{Transcription and translation}

The formation of the triple helix of collagen is a complex process that preludes with the transcription of collagen genes in the nucleus. It is modified in the ER, post translation and finally processed in the secretory vesicles of the Golgi apparatus, destined for excretion into the ECM. Almost all 28 collagen types follow the similar basic mechanism of triple helix formation and further processing.

Most collagen genes have complex intron-exon patterns, including 3-17 introns and mRNA of fibrillary collagen encoded by around 50 exons [26]. It gives rise to a different population of mRNA species due to alternate splicing, multiple initiation sites or a combination of both. For example, a longer form of collagen (COL2A) is expressed in chondro-progenitor cells, its shorter form (COL2B) is expressed in mature articular chondrocytes in which exon2 is excluded [27]. To discuss this in detail is however beyond the scope of this review.
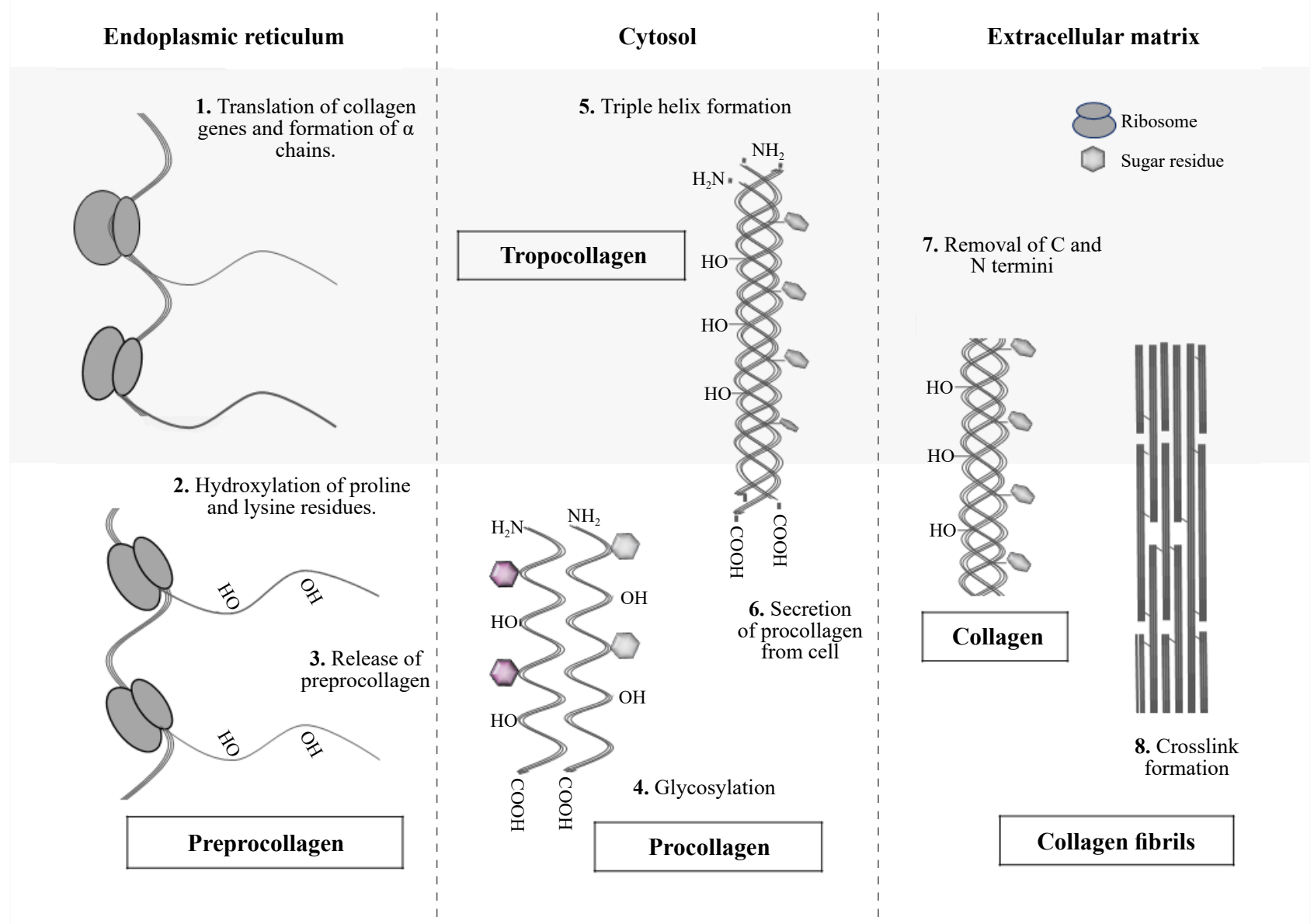

Figure 2. Step by step process for biosynthesis of collagen polypeptides in ribosomes and post-translational modifications of procollagen in cytosol for making collagen fibrils

\subsection{Post translational modifications}

Figure 2 depicts the flow of collagen biosynthesis in vivo. The precursor of collagen, preprocollagen is cotranslationally transported in the lumen of rough ER. The procollagen formed after removal of the signal peptide undergoes hydroxylation of specific proline and lysine residues by membrane-bound hydroxylases thereby yielding hydroxyproline (Hyp) and hydroxylysine (Hyl). The degree of hydroxylation of procollagen depends on the tissue and 
collagen type (Collagen I to XXVIII). The hydroxylated lysine residues further undergo a series of modifications like glycosylation, i.e., addition of galactose and glucose moieties and addition of oligosaccharides to asparagine residues at C- terminus [25].

\subsection{Secretion of collagen molecule and extracellular processing}

The polypeptide formation is initiated at $\mathrm{C}$ - terminus while regulation of fibril diameter is ensured by $\mathrm{N}$ - terminus. After the assembly of the procollagen molecule, the triple-helical structures are packed in the vesicles of the Golgi apparatus and released into ECM [26]. Further processing of procollagen includes the cleavage of $-\mathrm{C}$ and $-\mathrm{N}$ termini and spontaneous arrangement into ordered fibrillary structures called tropocollagen. These monomers are stabilized by hydrophobic and electrostatic interactions, which may further aggregate into five stranded fibrils $(1 \mathrm{~nm}$ and $1 \mu \mathrm{m}$ in diameters) and subsequently into larger collagen fibres ( $1 \mu \mathrm{m}$ to more than $10 \mu \mathrm{m}$ in diameter). The additional stability is imparted by the formation of covalent crosslinks contributing to the mechanical strength, and the stable network of the collagen fibres.

\section{Types of collagen}

Almost 28 different types of collagen (type I to XXVIII) have been reported [23] that vary in their size, length, amino acid composition (particularly proline and hydroxyproline), glycosylation of hydroxylated proline, etc. Glycine, proline and hydroxyproline are the most important amino acids of collagen and account for almost $50 \%$ of total protein content. Collagen forms can be subdivided into subfamilies (Figure 3) based on their supramolecular assembly as fibril forming collagen (e.g., I, II, III, V), basement membrane collagen (e.g., type IV, VII, etc.), microfibrillar collagen (e.g., VI), network forming collagen (X), fibril associated collagen (FACIT) (e.g., IX, XII), transmembrane collagen (e.g., XIII, XVII). Amongst the 28 different types of collagen, the most abundant types include type I, II and III that are fibril-forming collagens and are involved mainly in tissue strength, elasticity, mechanical integrity and water retention capacity. Each type of collagen has a distinct role in different tissues with varying expression levels. The distribution pattern of collagen type I, II and III which are most abundant and prominent in the human body are detailed below.

\subsection{Type I collagen}

It is the prototype molecule of the collagen family. It is one of the most abundant and most studied collagens in the body. It is the key structural component of several tissues including bone, skin, tendon, teeth, cornea, ligaments, etc. The structure and location however determine its function in the specific tissue [28]. In most of the tissues, it provides tensile stiffness. The dominant form of collagen type I consists of two COL1 $\alpha 1$ chains and one COL $1 \alpha 2$ chain translated from alpha 1 and alpha 2 gene (COLIA1 and COLIA2, respectively) mRNA. Homotrimer form of COL1 11 has been reported in tumours and foetal tissue, which is more resistant to cleavage, by collagenases. Amongst the various types of collagen, I to XIV are listed in Table 1.

\subsection{Type II collagen}

It is an important component of the cartilage in mammals that is required for synthesis and reconstruction of the connective tissues. It is dominant in cartilage and vitreous humor [29] and expressed in non-cartilaginous tissues like the notochord, eye, heart, brain during embryonic development [30]. Type II collagen is a heterotrimer consisting of three $\alpha 1$ (II) chains encoded by the COL2A1 gene. The alternate splicing of the COL2A1 gene results in two isoforms of type II collagen [26]; IIA is found during embryonic development and IIB is the dominant form in mature cartilage. Compared to collagen type I, it shows a higher degree of glycosylation of hydroxylysine residues.

\subsection{Type III collagen}

Type III collagen is the second most abundant type present in soft tissues. It is a homotrimer of three $\alpha 1$ (III) chains 
synthesis of which is controlled by the COL3A1 gene [30]. With exception of bones, it is widely distributed in collagen type I containing tissues including skin and vascular tissues, bowel, uterus [30]. It forms the mixed fibril with type I collagen, and it is the important constituent of elastic tissues. Progressive collagen loss has been associated with ageing as these proteins impart structural strength to the skin.

Almost all types of collagens are readily absorbed upon topical administration and hence largely used in the cosmetics and pharmaceutical industries. The gelatin (formed by irreversible denaturation of collagen) and BCP (HC) (Figure 3) are widely used in nutraceuticals-food and food ingredients. A number of natural and synthetic biopolymers like heparin, alginate and nylon- 6 can be blended with gelatin using electrospinning technique for biomedical applications [31]. Marine collagen peptides (particularly type III) improve healthy hair and nail growth, skin elasticity and hydration [17]. In East Asian countries like Japan, the hydrolyzed collagen obtained from porcine is widely used as a dietary supplement due to its easy availability and health benefits (especially the anti-ageing effect) [32].
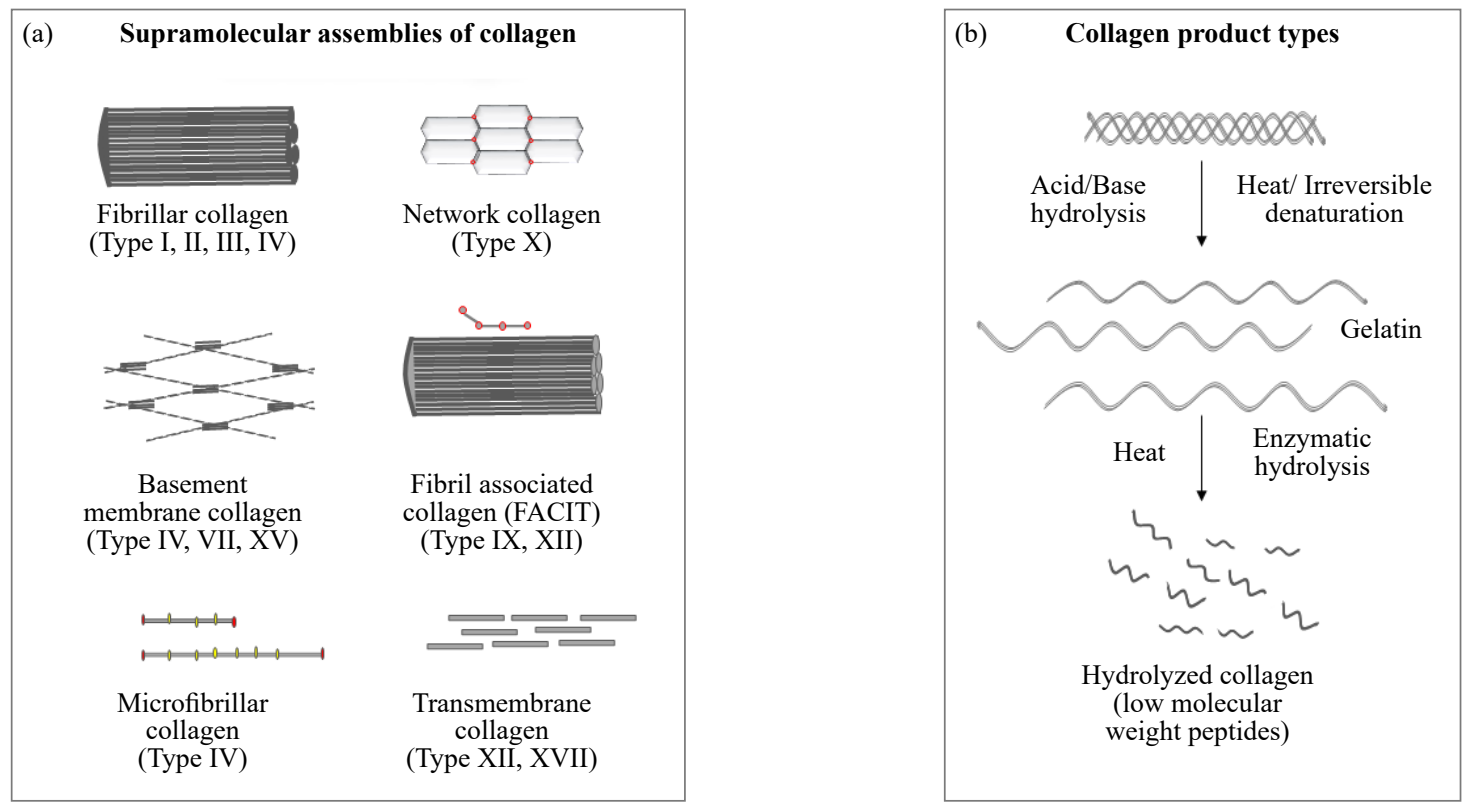

Figure 3. (a) Supramolecular assemblies of collagen fibrils formed by various arrangement of different types of collagen, and (b) the collagen product types, i.e., irreversible denaturation of collagen forming gelatin and hydrolyzed collagen

\section{Distribution of collagen}

The major function of collagen includes mechanical reinforcement of connective tissues of vertebrates. It surrounds the organs and holds specialized cells together in discrete units. Thus, it prevents the organs and tissues from losing or tearing their shape when exposed to rough movements [26]. In addition, collagen plays a regulating role in developing tissues, influencing the proliferation and differentiation of unspecialized cells [23].

\subsection{Musculoskeletal tissues (bone, cartilage, muscles, joints, etc.)}

These tissues are highly ordered nanostructured materials consisting of nanofibers embedded in the matrix. The composition and structure of the matrix and its interaction with fibres determine the biological properties of musculoskeletal tissues.

Bone is a highly structured composite material that is made up of organic and inorganic phases. The organic phase (proteins) consists mainly of type I collagen while the inorganic phase consists of hydroxyapatite nanocrystals (HAp) (Figure 4) [33]. The HAp embedded in the organic matrix containing proteins impart stiffness and strength to the bones. The HAp nanocrystals grow on the collagen fibrils in the process called nucleation, which is regulated by other non- 
collagenous proteins [34].

Cartilage is specialized shock absorbing connective tissue, which is composed of specialized cells called chondroblasts. These cells produce large quantities of ECM, which include collagen fibres that are a crucial component of the matrix of articular cartilage. It accounts for almost $40 \%$ of the organic composition of cartilage. It also forms an extensive network of collagen fibrils, providing cartilage with mechanical integrity.

\subsection{Skin}

Skin is one of the non-linear and visco-elastic tissues, which is composed of three well-defined layers: epidermis (outer), dermis (middle) and hypodermis (inner) (Figure 4) [35]. Dermal fibroblasts are involved in the production of collagen along with other ECM proteins. Collagen is one of the major protein components of the dermis that defines skin physiology and maintains its structure along with the elastin fibre network. In human skin, type I collagen make up $80-90 \%$ of collagen [6] followed by type III collagen (8-10\%) and type V collagen $(<5 \%)$ [36].

The young skin has well organized, tightly packed and intact collagen fibrils, which are fragmented or degraded as skin ages. Various internal and external factors (sunlight, pollution, smoking, etc.) also influence the physiological processes of skin ageing $[6,17]$.

Collagen also maintains the hydration of the skin, which is important to maintain its health and beauty. Most of the water in young skin is bound to collagen giving it structural and mechanical properties, however, as skin ages the water is found in tetrahedron or a free form with diminished solubility of mature collagen in water due to extensive crosslinks with skin ageing [37]. Ageing affects the dermal structure as aged fibroblasts synthesize less collagen.

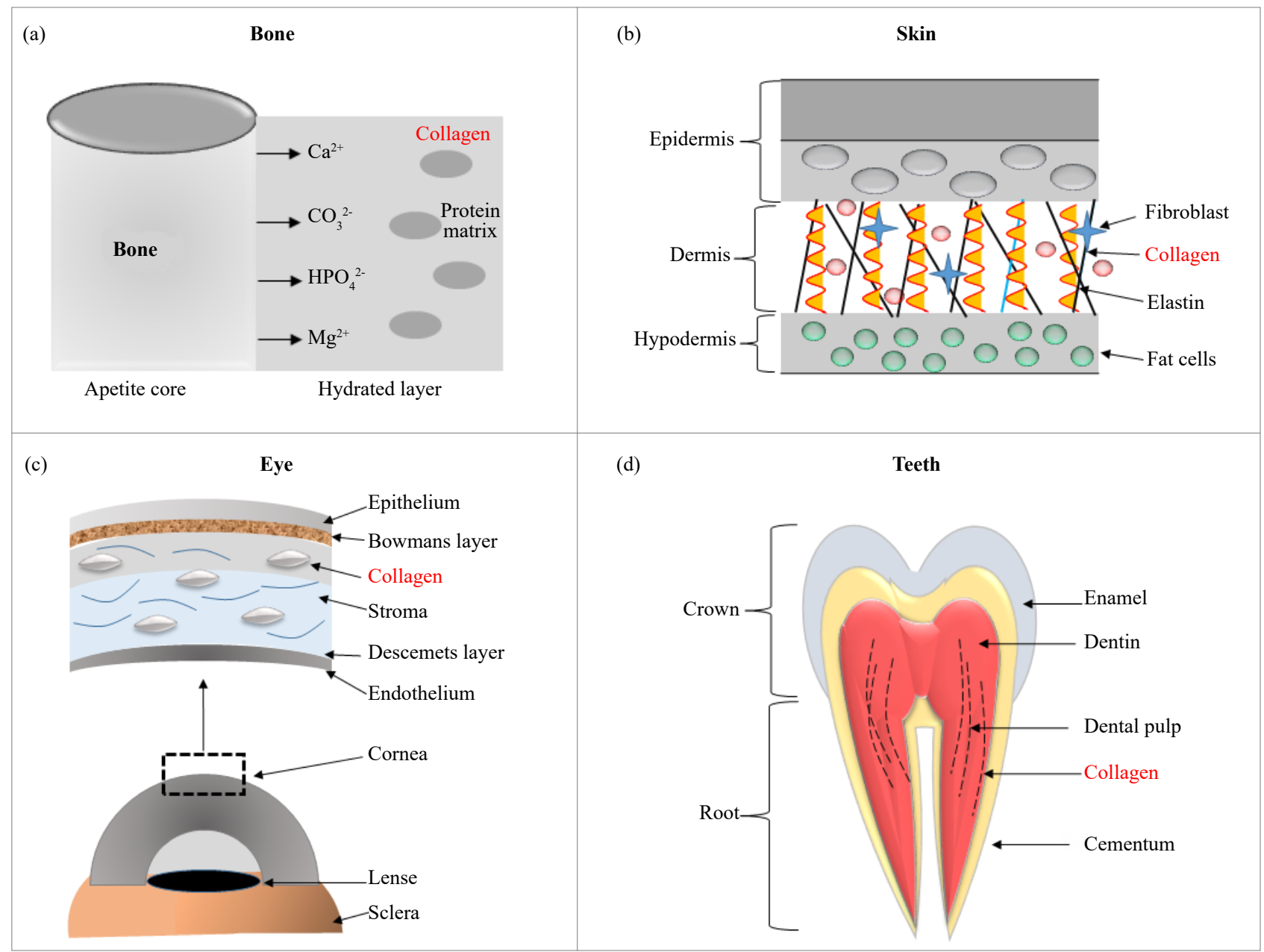

Figure 4. Distribution of collagen in skin, bone, eye, teeth of human 


\subsection{Cornea}

The cornea in the eye plays an important role in directing the light rays onto the retina to provide accurate vision [38]. The stable spherical shape of the cornea is maintained due to the complex network of collagen fibrils embedded in the homogenous matrix of proteoglycan and elastin, which imparts mechanical strength and stiffness to the stroma (Figure 4) [38].

In addition, the corneal transparency is dependent on the arrangement of these collagen fibres in the stroma. The stroma majorly contains type I collagen fibres while the basement membrane of the corneal epithelium contains type IV collagen [39]. In response to trauma to the corneal stroma, secretion of collagen fibrils occurs by keratinocytes, which align differently than the original stromal organization [40].

\subsection{Teeth}

A part of the tooth, also called a tooth crown consists of enamel, dentin, cementum and pulp tissue [41]. The dentin is composed of various fractions of ceramic (calcium HAp), protein (majorly type I collagen and small amounts of type III and V) and water. The combination of these three building blocks forms the mineralized collagen fibril, which is well organized around the long hollow cylinders called tubules [42]. The complex structure of dentin allows the teeth to be strong, tough and maintains structural integrity. The pulp of teeth contains type I and type III collagen in the extracellular matrix [43]. The cementum of teeth contains about 40-45\% of HAp and majorly type I collagen along with type III, V, VI, XII, XIV that are found in small proportions.

\subsection{Hair}

Collagen fibrils in hair follicles impart strength and elasticity to the growing hair. Its reduction increases the ageing phenotype, the breakage of hair and excess shading. As the human body ages, damaged DNA accumulates in the hair follicles causing proteolysis of collagen (usually type XVII) [44], which eventually leads to thinning and balding.

\subsection{Heart}

The cardiac fibroblasts produce a variety of proteins including collagen type I and III [45], which provides the scaffold that is necessary for the formation of the fibrous meshwork of the heart. The collagen fibrils along with other extracellular non-collagenous matrix proteins impart functional integrity to the heart [45].

\section{Sources of collagen}

\subsection{Bovine}

Bovine collagen is one of the major industrial sources of collagen due to its low immunogenicity and biocompatibility in most of the population [46]. Bovine type I collagen is isolated mainly from the Achilles tendon [1] and it is the major source of commercially available collagen. The isolation methods and tissue type may cause inconsistency in the composition of collagen, which also depends on the age, genetic inheritance of the donor population [46]. The transmission of diseases during extraction like bovine spongiform encephalopathy and viral vectors is a major concern in the usage of bovine collagen [47]. Around 3\% of the population is allergic to bovine collagen, which has encouraged the search for safer alternatives.

\subsection{Porcine}

Porcine collagen is widely used in industrial applications due to its low antigenicity and similarity with human collagen. It is obtained from the adult porcine dermis, small intestinal mucosa that is shown to be efficient in plastic and reconstructive surgery, skin and wound healing, etc. However, similar to bovine collagen, it poses the risk of zoonosis [1]. The use of porcine collagen is restricted in Middle East countries due to religious regions [2]. In East Asian 
countries like Japan, China the use of porcine collagen in various forms is a regular part of the diet (Bone broth, Ramen, confectionery products, etc.) due to the health and beauty benefits of porcine collagen peptides.

\subsection{Marine sources}

Marine collagen is of great interest due to its distinct biological, chemical and mechanical properties compared to animal-derived collagen [46]. It poses no risk of disease transmission like an animal and is considered as GRAS (Generally Recognized As Safe) by The United States Food and Drug Administration (FDA) [19]. The advantages of marine collagen include a high content of collagen fibres, greater absorption due to low molecular weight, low immunogenicity, the least ethical and religious issues, comparatively fewer regulatory and quality control problems, etc. Various sources of marine collagen include marine invertebrates and vertebrates like fishes, jellyfish, sponges, sea urchin, octopus, sea urchin, prawns, etc. The bones, skin, fins of fishes are reported to be an excellent source of collagen, which also reduce environmental pollution (they are the waste product of fish processing) [1].

\subsection{Rodent sources}

The rat-tail tendon (RTT) is a commonly used source of type I collagen in researchers compared to industrial use. It contains about $90-95 \%$ of type I collagen, which ensures higher yields upon extraction [46]. The research on type I-RTT collagen indicates that as the rat ages, there are significant changes in the chemical and mechanical properties of collagen. It becomes less elastic and more resistant to force.

\subsection{Other animal sources}

Few other animal sources include chicken, kangaroo tail, duck feet, equine tendon, alligator bone and skin, sheepskin and even humans. The recombinant human collagen is used due to its low immunogenicity compared to other sources.

\subsection{Chemically synthesized collagen}

Due to concerns like batch-to-batch variation, immunogenicity, etc. the synthetic sources like KOD (commercially name derived from the sequence of peptide (P-K-G) (P-O-G) (D-O-G)) have been researched in recent times [19]. This synthetic protein is made up of 36 amino acids that self-assemble to form nanofibers and hydrogels, which mimic the natural collagen.

\subsection{Synthetic collagen}

Various synthetic (non-native) sources of collagen have been developed using synthetic biology tools to produce contaminant-free animal-derived collagen [20,21]. These recombinant sources are devoid of heterogeneity across species, pathogen transfer and immunogenicity. For example, efforts have been made to produce recombinant human collagen (e.g., CLPs-collagen lie polymers, rhCOL-human collagen type III) in various expression systems like prokaryotic (Escherichia coli), eukaryotic (yeast, plants, insects, human cell lines) expression systems. The expression systems including $E$. coli and yeast are limited by their capability of post-translational modifications, i.e., hydroxylation that needs additional transduction of viral hydroxylases in these expression systems [48]. However, due to the faster growth rate and ease of genetic manipulations of yeast expression systems, multiple companies have adopted it as a host for industrial-scale production (Table 2). The other expression systems include plants [21], insects, (isolated) cultured insect cells [46], mammals, and cultured human cells [49]. The transduction of collagen encoding genes in the human cell line is more promising compared to that of non-mammalian cells due to its post-translational modification capacity. Studies have reported the identical properties of rhCOL produced in cultured human cells to that produced in vivo. However, the low product yields in these expression systems are insufficient to meet the industrial demand for collagen. 


\section{Applications of collagen}

Exceptional biocompatibility accompanied by weak antigenicity and biodegradability of collagen and collagenbased products makes it a central player in a wide range of applications.

\subsection{Collagen-based drug delivery systems}

In recent years, the interest in the use of collagen as a protein-based biomaterial has increased enormously. The well-known safety profile of collagen makes it a commonly used biomaterial as a carrier for various drugs and growth factors for treatments like cancer, periodontosis, corneal restructuring, etc. The morphological properties of collagenlike hydrophilicity, mechanical strength and biodegradability that can be controlled by polymer concentration, working voltage and degree of cross-linking for use in drug delivery systems [50].

\subsubsection{Nanosphere/microspheres}

These structures can be formed by the combination of electrostatic and electronic forces. The charge-charge interaction in between such systems is enhanced by sodium sulphate [51]. The nanoparticles enhance the uptake of compounds like anti-HIV drugs especially in macrophages thus offering an additional advantage of collagen-based drug delivery systems [50].

\subsubsection{Collage- based mini pellets}

Collagen mini pellets are tiny rods ( $\sim 1 \mathrm{~mm}$ in diameter and $\sim 15 \mathrm{~mm}$ in length) that are extensively used in Japan [51]. These cylindrical structures can carry large molecules like interferons, interleukins, and lysozymes to be administered subcutaneously for local delivery. Studies have shown that, when an atelocollagen (type I collagen) pellet is used as a carrier, bone morphogenetic proteins (BMPs) induce direct bone formation without cartilage being formed. Mini pellets have also been used for the local delivery of lysozymes and minocycline for periodontitis treatment [52].

\subsubsection{Collagen films}

Collagen films/disc/sheets $(0.01-0.5 \mathrm{~mm})$ are formed by air-drying the casted collagen preparations as a barrier membrane [50]. The drugs like steroids, hormones, antibiotics can be loaded onto the films by hydrogen bonding, covalent bonding or simply by entrapment [50]. Such films can be used for the treatment of corneal tissue infections [53], liver cancer etc. In one of the studies, the collagen films loaded with BMPs have shown direct osteoinduction without the formation of cartilage when placed in close contact with osteogenic cells [54]. ColoGide ${ }^{\circledR}$ by ColoGenesis is a commercially available sterile collagen sheet is guided tissue regeneration (GTR) membrane that can be used on the patients directly.

\subsubsection{Collagen shields/corneal shields}

Collagen shields are bandage contact lenses, which gradually dissolve in the cornea when applied to the ocular surface [52]. The shield dissolves and the entrapped drug from the collagen matrix are released by the flushing action of the eyes. The reported research by Bausch \& Lomb shows the production of collagen shields in various shapes and thicknesses to be used as contact lenses [51].

\subsubsection{Collagen sponges}

Collagen sponges form an excellent system for the treatment of severe burns, wound dressing, leg ulcers, etc., they are also used for the delivery of antibiotics, steroids, growth factors for wound healing and bone implants. The delivery of drugs in such formulations is controlled by polymer hydration and swelling to form a gel, diffusion of drug through the gel by erosion. Upon contact with the wound, collagen sponges can absorb a large quantity of tissue exudate [51]. These systems smoothly adhere to the wet wounds; provide a moist microclimate and acts as a shield against mechanical 
injury and secondary bacterial infection. Application of a collagen sponge with growth factor are known to facilitate dermal and epidermal wound recovery process [55] by infiltration of neutrophils.

The sponges are produced from bovine skin by acidification at $\mathrm{pH} 3$ followed by its stabilization. The sponge layer thus formed can be combined with materials like fibronectin, elastin or glycosaminoglycans. The efficiency of these systems can be enhanced by co-polymerization of crosslinked collagen with polymers like polyhydroxyethylmethacrylate (PHEMA) for improved tensile strength and hydrophilic properties.

SpongeCol ${ }^{\circledR}$ by Sigma-Aldrich is a commercially available collagen sponge used as a scaffold for 3D cell culture. It is composed of highly purified Type I collagen which supports the attachment, proliferation, and function of cells.

\subsubsection{Collagen gels/ hydrogels}

Hydrogels are three-dimensional structures with the ability to absorb the large amount of body fluid and water [56]. Hydrogel systems like Polyacrylamide-grafted-pectin have been studied extensively to develop transdermal drug delivery systems [57, 58]. Collagen hydrogels are widely used biocompatible injectable systems in the form of (a) suspension of collagen fibres; (b) non-fibrillar viscous solutions in aqueous media [52]. These systems are composed of collagen cross-linked with various chemicals like aldehydes, polyphenols, carbodiimides, poly epoxy compounds, etc. Collagen hydrogels have the unique property of maintaining structural integrity even after soaking the fluids. A collagen composite made with PHEMA has been reported as a drug delivery system for anticancer drugs. Atelocollagen are gels produced by elimination of the telopeptide residues using pepsin, which are used as a carrier to repair cartilage defects in chondrocytes [59].

\subsection{Musculoskeletal tissue engineering}

A severe bone loss or damage needs the replacement and restoration of bone function. The process of development and regeneration of bone requires coordinated cell proliferation, differentiation, migration followed by remodelling of ECM [14]. Further, the scaffolds used for bone regeneration must promote the differentiation of immature progenitor cells into osteoblasts (osteoinduction); induce the ingrowth of surrounding bone (osteoconduction) followed by integration into the surrounding tissue (osseointegration). Such stimulation of osteoblasts has been observed in $\mathrm{ZnO}$ incorporated polycaprolactone (PCL) scaffolds [60]. Unlike conventional bone grafts, recent advances in regenerative medicine have increased the possibility of repairing the bone damage with the combination of biomaterials [58] and growth factors (like transforming growth factor- $\beta$ [TGF- $\beta]$, basic fibroblast growth factor [bFGF], BMPs, etc.) [61]. Similar to chitosan, hyaluronic acid (HA), alginate, heparin; collagen has been widely used for the synthesis of Injectable hydrogels for cartilage and bone tissue engineering. The common therapeutic target for bone regeneration includes osteoconductive scaffolds, which plays a major role in maintaining cell function and guiding tissue growth and has the highest bone renovation potential [62]. Osteoblast conditioning has been reported as a viable strategy for the development of such scaffolds [63]. Type I collagen is a widely used scaffold material due to its weak antigenicity and biodegradability for bone engineering and it serves as the template for mineralization [62]. To improve the performance of collagen-based scaffolds, a variety of materials have been explored like bioceramic scaffolds (biocomposites based on calcium phosphate, calcium silicate, etc.), carbon-based components (carbon nanotubes, graphene oxide, etc.), natural polymer components (glycosaminoglycans, silk fibroin, etc.), artificial polymer components (polycaprolactone, polyglycolic acid, polyvinylalcohol) [34, 62]. These scaffolds can also provide a structure for cell attachment to produce a new cartilage matrix in case of cartilage repair. The mechanical properties of biopolymers is largely depend on the morphology, crystallinity, crosslinking, molecular orientation, concentration, etc. which can be further enhanced by blending with other bio-based reinforcement material [31]. In recent years, multilayer collagen membranes are explored for tendon tissue engineering [64] which involves modification or fabrication of collagen scaffolds for improved properties like porous 3D structure, bioresorbable, similar mechanical properties to native tissues, etc. [64].

\subsection{Skin and wound healing}

Wound healing is a complex process in which collagen contributes to hemostasis by recruiting platelets to the wound site in the process of chemotaxis [65]. The clot formed by this interaction provides the matrix for inflammatory 
cell influx. The success of this process depends on the coordination of cytokines, chemokines and growth factors facilitating the wound closure by binding to ECM proteins like collagen. During the early stages of wound healing, fibroblasts produce more amount of type III collagen than under normal conditions. In the healing wound, type III collagen is progressively replaced by type I collagen [66].

Collagen being one of the important components of dermal ECM, it is frequently used in protein-based scaffolds for skin wound healing in various forms such as powder, amorphous gels/pastes, gel-impregnated dressing, sheets and pad. Collagen scaffolds provide mechanical support, reduces fluid loss from the wound area and facilitates fibroblasts migration in the wound. They also absorb reactive oxygen and nitrogen species and act as a competitive substrate for collagenases, which reduces the enzymatic degradation of tissue. The mechanical properties of collagen for tissue engineering applications can be enhanced by blending it with PCL [67]. The poly ( $\varepsilon$-caprolactone) nanofibers have been shown to have improved hydrophilicity with collagen coating, and enhanced mechanical strength with $\mathrm{TiO}_{2}$ entrapment to be used in wound healing [68]. Few of the currently available collagen-based wound dressings include (a) WounDress ${ }^{\circledR}$ by Colloplast, which are collagen hydrogel-based dressing for wounds. It promotes autolytic debridement by re-hydrating and softening dry wounds and necrotic tissue; (b) Puracol ${ }^{\circledR}$ plus collagen dressing by Medline; (c) Apligraf ${ }^{\circledR}$ by Organogenesis, which restores the fibroblast function at wound base and normalize the ECM production.

Compared to collagen, the $\mathrm{HC}$ can be easily absorbed, transported to the systemic circulation and elicit biological activities. They send a false signal to fibroblast cells to synthesize new collagen fibres. The chemotactic properties of these peptides promote cell migration and proliferation, which is an important process in wound healing [69]. Stimulen ${ }^{\mathrm{TM}}$ by Southwest technologies is concentrated dispersion of modified collagen (HC) in gel form used for wound healing. Hycol TM by Sanara Medtech is available in powdered as well as gel form as wound dressings.

\subsection{Corneal tissue engineering}

Most tissue engineering approaches include combining cells with a biomaterial-based scaffold, which can replicate the real tissue. The major parameters in determining an engineered tissue are the type of material used and how the scaffold is synthesized. The ideal scaffold for corneal tissue engineering should possess good optical properties and significant mechanical strength [70]. A wide variety of tissues has been used for corneal tissue engineering like acellular corneal stroma, silk fibroin, collagen, etc. Collagen being the major component of corneal stroma it is the most promising material in corneal scaffolds. Its mechanical properties can be improved by crosslinking and composting. To maintain corneal transparency, micropatterned collagen scaffolds have been reported which can regulate cellular behaviour [53]. The source and age of collagen play a significant role in the final physical properties of scaffolds like the structure, optical properties, biocompatibility, etc. Various types of collagen scaffolds for corneal tissue engineering include hydrogels, films, and sponges. One of the scaffolds under investigation is vitrigel, which has been successfully used in animal models to grow and transplant corneal epithelium [71].

\subsection{Teeth engineering}

Tooth damage or loss is a common and frequently occurring problem. Therapies such as dental implants, artificial dentition and tooth transplantation are widely employed. However, the reinstallation of teeth function is still questionable with these treatments. Amongst the various approaches like novel cell pellet, engineering, genemanipulated tooth-engineering, chimeric tooth-engineering, etc. the usage of synthetic scaffolds is the most accepted technique. Injecting a soft scaffold matrix loaded with cells and growth factors is most favorable in areas difficult to access like the pulp cavity [72]. It is possible to promote tooth organogenesis by cultivating postnatal dental stem cells (DPSCs) on a well-structured bioengineered 3D scaffold. The collagen scaffolds have been shown the growth of DPSCs into the scaffold material. The hybrid of DPSCs, collagen scaffolds and dentin matrix protein-1 (DMP-1) has shown to induce the formation of an organized matrix similar to pulpal tissue [72].

\subsection{Foods and nutraceuticals}

The beauty and health benefits make collagen an exceptional ingredient of diet especially in countries like Japan, Korea, etc. Apart from citrus fruits, leafy vegetables, nuts, mushrooms, etc. collagen-rich sources like pig trotters, jelly 
drinks, confectionery products, suppon, turtle blood, bone broth are widely included in the Japanese diet. Collagen is widely used as an edible coating material for sausages and foods [2]. It acts as a barrier membrane providing structural integrity as well as vapour permeability to food products. It is also used as a food additive to improve the rheological properties of sausages, meat, etc. It is widely reported that collagen supplementation with dietary ingredients modulates the skin ageing process. Such supplements can be obtained by extracting the collagen from various sources like animals, marine sources, etc., and it is available in various forms like powder, capsules as well as food and drinks additives. Collagen is used in juices and soups to improve its functional and nutritional value along with its protein content. In the United States, bone broth is considered a healthy alternative for coffee. The addition of collagen peptides in the probiotic drinks containing prebiotic fibre along with vitamin $\mathrm{C}$ has been shown to stimulate the growth of beneficial gut flora by Malaysia Dairy Industries (MDI). Few commercially available food products include, rose collagen gummy by Natural Oceania, collagen detox beverage, collagen infusion by Qwell and Vital collagen water by Vital Proteins.

$\mathrm{BCP}$ or HC are collagen peptides, which are shown to have a greater effect on health benefit due to bioavailability, rapid absorption in digestive tract and blood, faster accumulation in skin, etc. [2]. As hydrolyzed collagen is dispersible in water and is well absorbed in the body, it is more suitable for digestion. Bioavailability of these peptides is increased as it has the capacity to bind the $\mathrm{Ca}+$ ions making it more compatible inside our body. Hydrolyzed form of collagen is preferred for cold storage food items as it minimizes any damage to cells/tissues during low-temperature storage without affecting the product's sensorial properties [73].

Gelatin is one of the hydrolyzed products of collagen, which is commonly used as a binder in various products like candies, jellies, marshmallows, gelatin desserts, etc. It is a part of the majority of confectionery products. For example, gelatin dessert by JELL-O.

\subsection{Cosmetics}

The abundance and significance of collagen in the human body make it an ideal protein for cosmetics applications. The ageing of the skin usually results in the structural modifications of dermis which is induced by the loss of internal cohesion and due to rupture or decrease of collagen fibres. The intake of collagen peptides enhance the growth of fibroblasts and restores the functional organization of skin [69]. The HC has been widely used as bioactive components in collagen facial masks, hair masks, lip masks, etc. It is reported that collagen hair mask reduce hair breakage, split ends, make the hair strong and shiny by supporting hair follicles regeneration. Collagen has been reported to increase the volume of hair by strengthening the hair follicles and keeping them moist. Although greying of hair is common with ageing effect, collagen may act as an antioxidant that negates the hair greying effect. Collagen in combination with hyaluronic acid and sunflower oil has been reported to plump the fine lines on lips and soften them. Collagen masks on the other hand are popular beauty products for quick collagen lip treatment. The lip masks are more famous for making lips fuller and plumper. Few of the commercially available personal care products containing collagen include: oral collagen supplements by Oziva (anti-ageing and young looking skin), natural collagen sheet mask by Rael, hair mask by Kerseel (deep hair repair), lip mask for lip plumping by Dot \& Key, hair shampoo for fuller and healthier by OgX and moisturizer by L'Oreal (smoothening wrinkles).

\subsection{Novel biomaterials}

Conventional biomaterials are easy to design and their characteristics are well explored in chitosan [74], sodium alginate $[75,76]$, etc. The research in recent years has focused on designing the next generation biomaterial using combinations as the composition of scaffold and properties of biomaterials used for tissue engineering have a major impact on the regeneration of tissues. Recently the novel designs using two or three biomaterials like chitosan, hyaluronic acid, alginate, heparin, and collagen are being explored, as the single material cannot meet all the requirements ideal for biological applications. For example, biodegradable scaffolds of collagen and sodium alginate [77] and recombinant human collagen/chitosan hydrogels [78] are reported for soft tissue engineering applications, collagensilk composites have been used to regenerate the cartilage [79]. To overcome the traditional tissue or bone grafting method the chitosan-collagen composites are used for the development of synthetic graft to enhance the mechanical strength of the graft, as well as healing rate and bone adhesion rate [80].

Further, the increasing usage of personal care products hast offered a significant advancement in the cosmetic 
industry. For example, the combination of silk and collagen face masks have shown to be effective in overall skin health improvement.

\section{Market potential of collagen as a biomaterial}

The collagen market is segmented on the basis of source such as bovine, poultry, porcine, marine; product type like gelatin, hydrolyzed collagen, native collagen; collagen types, i.e., type I, type II, type III, etc; a form of collagen such as the powder or liquid; its function stabilizer, emulsifier, etc.; application in food products, beverages, nutraceuticals and dietary supplements, cosmetics and personal care, etc.; and by region, i.e., North America, Europe, Asia Pacific, South America and Middle East Asia.

Easy availability of collagen sources has been reported by Grand View Research [81] to increase the production of collagen products in the forecast period of 2020-2027 at the estimated CAGR of 5.9\%. The increasing demand for collagen in food and beverages, cosmetics, medical applications are anticipated to drive the collagen demand. The major of the share of collagen market is dominated by Europe and North America with an increasing application of collagen in food, nutraceuticals and cosmetics.

The North American region is dominated by countries like the United States and Canada due to the increasing demand for collagen supplements amongst health-conscious populations. Gummy food products are major confectionery products to drive the ascending demand for collagen in Mexico and Canada. Based on the product type the market segment in this region was dominated by hydrolyzed collagen products and gelatin. Figure 5 shows the global hydrolyzed collagen distribution by region.

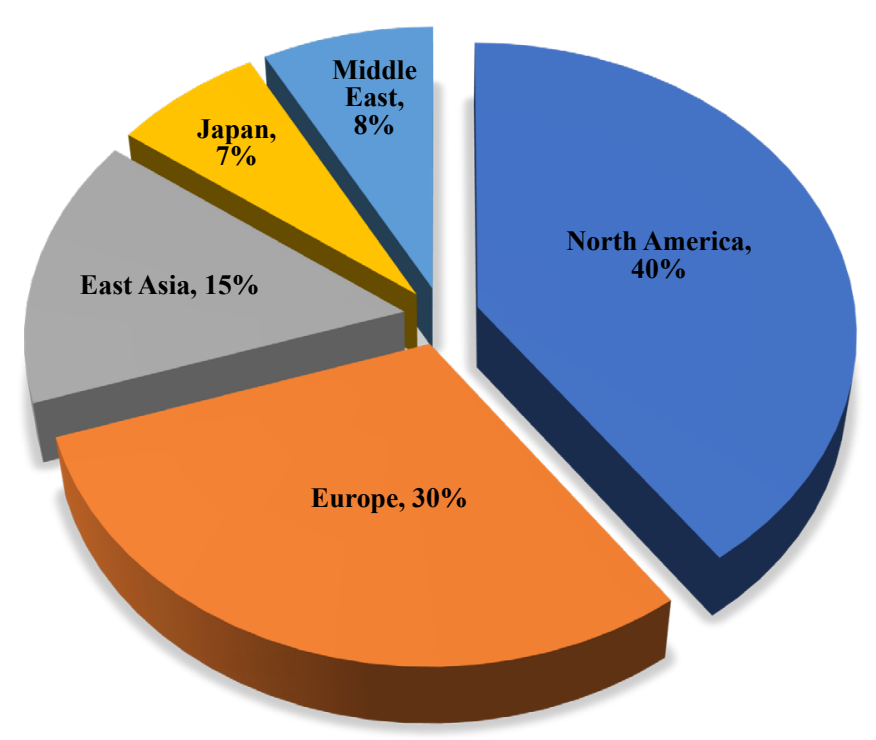

Figure 5. Global hydrolyzed collagen market distribution by region 2020-2027

According to Data Bridge Market Research, Asia pacific is currently reported to lead the global market for marine and vegan collagen [82]. The increase in the trend of cosmetic surgeries and advanced skin treatments has been the major factor in the rising demand for collagen applications. In addition, the rise in disposable income and increase in the vegan population in this region has contributed to it. The Asia Pacific region is dominated by countries like China, India due to the huge population and demand for cosmetics amongst consumers. Based on the types, the type I segment is dominating in this region due to its anti-ageing effect and usage in cosmetics. Excessive use of marine collagen in the beauty industry is expected to boost the market in this region. 
Table 2. The global market value of various forms of collagen

\begin{tabular}{|c|c|c|c|}
\hline Type & Market value & Predicted CAGR & Reference \\
\hline Collagen & $\begin{array}{l}\text { USD 3,603.2 million } \\
\text { in } 2021\end{array}$ & $8.3 \%$ forecast period 2021 to 2027 & $\begin{array}{l}\text { https://www.gminsights.com/industry-analysis/collagen- } \\
\text { market }\end{array}$ \\
\hline Gelatin* & $\begin{array}{l}\text { USD } 1,577.1 \text { million } \\
\text { in } 2020\end{array}$ & 8\% CAGR through 2027 & $\begin{array}{l}\text { https://www.gminsights.com/industry-analysis/collagen- } \\
\text { market }\end{array}$ \\
\hline Hydrolyzed collagen** & $\begin{array}{l}\text { USD } 825 \text { million } \\
\text { in } 2018\end{array}$ & $\sim 8 \%$ forecast period 2019 to 2029 & $\begin{array}{l}\text { https://www.transparencymarketresearch.com/ } \\
\text { hydrolyzed-collagen-market.html }\end{array}$ \\
\hline Fish collagen & $\begin{array}{l}\text { USD } 250 \text { million } \\
\text { in } 2018\end{array}$ & $\sim 8 \%$ forecast period 2019 to 2027 & $\begin{array}{c}\text { https://www.transparencymarketresearch.com/fish- } \\
\text { collagen-peptides-market.html }\end{array}$ \\
\hline Collagen peptides & $\begin{array}{l}\text { USD } 599 \text { million } \\
\text { in } 2020\end{array}$ & $5.8 \%$ through 2025 & $\begin{array}{l}\text { https://www.marketsandmarkets.com/Market-Reports/ } \\
\text { collagen-peptide-market-248590980.html }\end{array}$ \\
\hline Marine collagen & $\begin{array}{l}\text { USD } 778 \text { million } \\
\text { in } 2021\end{array}$ & $7.9 \%$ forecast period 2021 to 2026 & $\begin{array}{l}\text { https://www.researchandmarkets.com/reports/5310947/ } \\
\text { marine-collagen-market-by-type-type-i-type }\end{array}$ \\
\hline
\end{tabular}

*Majorly used in food industry

**Majorly used in food supplements, beverages, food and nutraceutical industry

In the Middle East and Africa, bovine collagen applications are increasing due to its easy availability. In addition, the demand for non-GMO is increasing in these regions due to $100 \%$ natural antibiotics demand among individuals. The veganism trend across the world however has influenced the collagen obtained from non-vegan sources like animals, marine, etc. Europe is dominated by bovine, porcine collagen source usage. The global vegan collagen market is expected to account for USD 0.9 billion by 2018 .

The European collagen market is dominated by countries like Germany, the United Kingdom due to the increasing demand for nutraceutical supplements amongst athletes. Due to the daily consumption of gelatin, this segment is dominating amongst product types.

\section{Sustainable production of collagen using synthetic biology platform}

Animals account for the majority of collagen sources available in the market; however, the transmission of diseases, allergy and immunogenicity caused by bovine and porcine-derived collagen pose an additional risk. These problems can be addressed by using human-derived collagen; however, the use of human placenta or skin-derived collagen is limited by ethnicity, the genotype of tissue, age, etc. which has encouraged the search for alternative sources of collagen.

In recent years, the synthesis of recombinant collagen is widely experimented in various expression systems including bacteria [83], yeast [84], insects [85], plants [21] and animal cell cultures. The coexpression of type III human collagen in bacteria with prolyl and lysyl hydroxylases have has shown to yield up to $90 \mathrm{mg}$ of collagen per litre [83]. The recombinant collagen produced in E. coli has been reported to support the human umbilical endothelial cells. Similar strategies are reported for the expression of human collagen type III in the insects and yeast cells [86]. The recombinant human collagen type I (RHCI) derived from tobacco plants have has been used to fabricate the hydrogels for grafting corneal implants [21].

The recombinant collagen although preferable, their production at commercial scale is difficult. However, new methods for sustainable collagen production using synthetic biology approaches may make non-animal collagen, a techno-economically viable biomaterial. The recent advancements with novel expression systems like recombinant yeast have been shown to exhibit commercial acceptability (Table 3). The plant-based expression system for collagen production has the advantage of obtaining high yields. One of the less explored expression systems for such biomaterial expression is green algae like Chlamydomonas reinhardtii [87], which is reported to be the robust platform for the expression of human therapeutic proteins [88]. The advantage of green algae platform is the less environmental impact due to their sunlight and carbon utilization ability, they are easy to cultivate with minimum nutrient requirements [88]. Considering the non-animal origin of recombinant collagen using novel expression systems, wide acceptance and sustainable production can be expected. 
Table 3. Various studies done for commercial application of recombinant collagen to serve various applications using synthetic biology platform

\begin{tabular}{|c|c|c|c|}
\hline No. & Company & Strain & Reference \\
\hline 1 & Modern meadow & $\begin{array}{l}\text { Recombinant Pichia pastoris producing bovine } \\
\text { type III collagen }\end{array}$ & US Patent Application 20190092838 \\
\hline 2 & $\begin{array}{l}\text { Cohesion Technologies, Inc., Palo Alto; } \\
\text { Genotypes, Inc., Pacifica, both of CA (US) }\end{array}$ & $\begin{array}{l}\text { Recombinant yeast producing bovine collagen } \\
\text { type I } \alpha \text { chains and gelatin }\end{array}$ & WO 2001/034647 \\
\hline 3 & $\begin{array}{l}\text { Fuji film manufacturing Europe B.V., } \\
\text { Tilburg, NL }\end{array}$ & $\begin{array}{l}\text { Recombinant yeast producing collagen silver } \\
\text { halide emulsion for photographic use }\end{array}$ & DE69823790D1 \\
\hline 4 & $\begin{array}{l}\text { Cohesion Tech Inc. (US) } \\
\text { Pharming holding NV (NL) }\end{array}$ & Fertilized oocytes of non-human mammals & US-5895833-A \\
\hline
\end{tabular}

\section{Conclusion}

This review article attempts to explain the synthesis and types of collagen, their sources and distribution in the human body and their applications. Collagen is the most abundant protein in the human body with around 28 different types discovered to date owing to its characteristic triple-helical structure and amino acid composition. Each type of collagen exhibit a distinct role at a specific location in the body making it a versatile molecule for various applications including tissue engineering, cosmetics, food and nutraceuticals. The chimeric structures of collagen is a potential area, which includes structure different from bacterial collagen that can be synthesized using genes from different species. It can also include other proteins like silk, elastic, etc. that makes collagen a next-generation biomaterial for expanded applications. The distinct properties of collagen such as mechanical strength, thermal stability can be enhanced by the incorporation of macro or nanosized scaffolds of other biopolymers including chitosan, silk, sodium alginate, heparin which are extensively used in tissue engineering applications, drug delivery, etc.

The current collagen market is largely dependent on the collagen obtained from animals and birds, however, the outbreak of diseases originating from these sources need the exploration of alternative sources. Marine sources of collagen are widely used in various applications like food, nutraceuticals with economic consideration. In the food industry, it is widely used as edible films, coating material and additives to improve product quality. The other forms of collagen, i.e., HC and BCP are extensively used in the food industry due to their higher water holding capacity and health benefits. The usage of animal collagen especially porcine is restricted in Middle East countries due to religious reasons while pig trotters are widely used in East Asian countries for broth preparation considering their nutritional value. The limitations of animal sources of collagen have offered new opportunities to researchers and scientists for exploring alternative sources like plants and algae. The rapid development in synthetic biology tools to produce synthetic collagen can overcome the major issues of contamination, disease transmission, and religious limitations. It is expected to meet the rising demand for collagen in near future considering the high yield of this molecule in plant, algae expression systems.

The vegan platform can make the synthetic collagen cost-effective, biocompatible, eco-friendly and sustainable. Exploring such platforms would benefit a broader population including customers as well as researchers and industrialists in future.

\section{Conflict of interest disclosures}

The authors confirm that, authors have no conflicts of interest to declare that are relevant to the content of this article.

\section{Acknowledgment}

The authors express their thanks to Varun Damle for correcting the writing errors. 


\section{References}

[1] Silvipriya KS, Kumar KK, Bhat AR, Kumar BD, John A, Lakshmanan P. Collagen: Animal sources and biomedical application. Journal of Applied Pharmaceutical Science. 2015; 5(3): 123-127. Available from: doi: 10.7324/ JAPS.2015.50322.

[2] Hashim P, Ridzwan MM, Bakar J, Hashim MD. Collagen in food and beverage industries. International Food Research Journal. 2015; 22(1): 1-8. Available from: http://www.ifrj.upm.edu.my/22\%20(01)\%202015/(1).pdf [Accessed 15th October 2021].

[3] Rico-Llanos GA, Borrego-González S, Moncayo-Donoso M, Becerra J, Visser R. Collagen type I Biomaterials as scaffolds for bone tissue engineering. Polymers. 2021; 13(4): 599. Available from: doi: 10.1007/s00068-006-60478.

[4] Formisano N, van der Putten C, Grant R, Sahin G, Truckenmüller RK, Bouten CV, Kurniawan NA, Giselbrecht S. Mechanical Properties of Bioengineered Corneal Stroma. Advanced Healthcare Materials. $2021 ; 2100972$. Available from: doi: 10.1002/adhm.202100972.

[5] Pragnère S, Auregan JC, Bosser C, Linglart A, Bensidhoum M, Hoc T, Nouguier-Lehon C, Chaussain C. Human dentin characteristics of patients with osteogenesis imperfecta: Insights into collagen-based biomaterials. Acta Biomaterialia. 2021; 119: 259-267. Available from: doi: 10.1016/j.actbio.2020.10.033.

[6] Reilly DM, Lozano J. Skin collagen through the lifestages: Importance for skin health and beauty. Plastic and Aesthetic Research. 2021; 8: 2. Available from: doi: 10.20517/2347-9264.2020.153.

[7] Du M, Chen J, Liu K, Xing H, Song C. Recent advances in biomedical engineering of nano-hydroxyapatite including dentistry, cancer treatment and bone repair. Composites Part B: Engineering. 2021; 215 : 108790. Available from: doi: 10.1016/j.compositesb.2021.108790.

[8] Zhao X, Zhang X, Liu D. Collagen peptides and the related synthetic peptides: A review on improving skin health. Journal of Functional Foods. 2021; 86: 104680. Available from: doi: 10.1016/j.jff.2021.104680.

[9] Mistry K, van der Steen B, Clifford T, van Holthoon F, Kleinnijenhuis A, Prawitt J, Labus M, Vanhoecke B, Lovat PE, McConnell A. Potentiating cutaneous wound healing in young and aged skin with nutraceutical collagen peptides. Clinical and Experimental Dermatology. 2021; 46(1): 109-117. Available from: doi: 10.1111/ced.14392.

[10] Cziperle DJ. Avitene ${ }^{\mathrm{TM}}$ Microfibrillar Collagen Hemostat for Adjunctive Hemostasis in Surgical Procedures: A Systematic Literature Review. Medical Devices: Evidence and Research. 2021; 14: 155-163. Available from: doi: 10.2147/MDER.S298207.

[11] Ahmed Z, Powell LC, Matin N, Mearns-Spragg A, Thornton CA, Khan IM, Francis LW. Jellyfish Collagen: A Biocompatible Collagen Source for 3D Scaffold Fabrication and Enhanced Chondrogenicity. Marine drugs. 2021; 19(8): 405. Available from: doi: 10.3390/md19080405.

[12] Vichare R, Hossain CM, Ali KA, Dutta D, Sneed K, Biswal MR. Collagen-based nanomaterials in drug delivery and biomedical applications. In: Hriday B, Chowdhury MH, Sudipta S. (eds.) Biopolymer-Based Nanomaterials in Drug Delivery and Biomedical Applications. Academic Press; 2021. p. 427-445. Available from: doi: 10.1016/ B978-0-12-820874-8.00008-7.

[13] Joshi R. Collagen Biografts for Tunable Drug Delivery. Springer International Publishing; 2021. Available from: doi: 10.1007/978-3-030-63817-7.

[14] Albu MG, Titorencu I, Ghica MV. Collagen-Based Drug Delivery Systems for Tissue Engineering. In: Rosario P. (ed.) Biomaterials Applications for Nanomedicine. IntechOpen; 2011. p.333-358. Available from: doi: $10.5772 / 22981$.

[15] Dille MJ, Haug IJ, Draget KI. Gelatin and collagen. In: Glyn OP, Peter AW. (eds.) Handbook of Hydrocolloids. Woodhead Publishing; 2021. p.1073-1097. Available from: doi: 10.1016/B978-0-12-820104-6.00028-0.

[16] Piao Y, You H, Xu T, Bei HP, Piwko IZ, Kwan YY, Zhao X. Biomedical applications of gelatin methacryloyl hydrogels. Engineered Regeneration. 2021; 2: 47-56. Available from: doi: 10.1016/j.engreg.2021.03.002.

[17] Lupu, MA, Gradisteanu Pircalabioru G, Chifiriuc MC, Albulescu R, Tanase C. Beneficial effects of food supplements based on hydrolyzed collagen for skin care. Experimental and Therapeutic Medicine. 2020; 20(1): 1217. Available from: doi: 10.3892/etm.2019.8342.

[18] Zhao X, Zhang X, Liu D. Collagen peptides and the related synthetic peptides: A review on improving skin health. Journal of Functional Foods. 2021; 86: 104680. Available from: doi: 10.1016/j.jff.2021.104680.

[19] Avila Rodríguez MI, Rodriguez Barroso LG and Sánchez ML. Collagen: A review on its sources and potential cosmetic applications. Journal of Cosmetic Dermatology. 2018; 17(1): 20-26. Available from: doi: 10.1111/ jocd. 12450 . 
[20] Akiyama Y, Ito M, Toriumi T, Hiratsuka T, Arai Y, Tanaka S, Futenma T, Akiyama Y, Yamaguchi K, Azuma A, Hata KI. Bone formation potential of collagen type I-based recombinant peptide particles in rat calvaria defects. Regenerative Therapy. 2021; 16: 12-22. Available from: doi: 10.1016/j.reth.2020.12.001.

[21] Haagdorens M, Edin E, Fagerholm P, Groleau M, Shtein Z, Ulčinas A, Yaari A, Samanta A, Cepla V, Liszka A, Tassignon MJ. Plant Recombinant Human Collagen Type I Hydrogels for Corneal Regeneration. Regenerative Engineering and Translational Medicine. 2021: 1-15. Available from: doi: 10.1007/s40883-021-00220-3.

[22] Ramachandran GN, Kartha G. Structure of collagen. Nature. 1954; 174(4423): 269-270. Available from: doi: $10.1038 / 174269 \mathrm{c} 0$.

[23] Ricard-Blum S. The collagen family. Cold Spring Harbor perspectives in biology. 2011; 3(1): a004978. Available from: doi: 10.1101/cshperspect.a004978.

[24] Shoulders MD, Raines RT. Collagen structure and stability. Annual review of biochemistry. 2009; 78: 929-958. Available from: doi: 10.1146/annurev.biochem.77.032207.120833.

[25] Scott I, Yamauchi M, Sricholpech M. Lysine post-translational modifications of collagen. Essays in biochemistry. 2012; 52: 113-133. Available from: doi: 10.1042/bse0520113.

[26] Gelse K, Pöschl E, Aigner T. Collagens - structure, function, and biosynthesis. Advanced drug delivery reviews. 2003; 55(12): 1531-1546. Available from: doi: 10.1016/j.addr.2003.08.002.

[27] Matsushita H, Blackburn ML, Klineberg E, Zielinska-Kwiatkowska A, Bolander ME, Sarkar G, Suva LJ, Chansky HA, Yang L. TASR-1 regulates alternative splicing of collagen genes in chondrogenic cells. Biochemical and biophysical research communications. 2007; 356(2): 411-417. Available from: doi: 10.1016/j.bbrc.2007.02.159.

[28] Byers PH, Bonadio JF. The molecular basis of clinical heterogeneity in osteogenesrs imperfecta: Mutations in type I collagen genes have different effects on collagen processing. In: June KL, Charles S. (eds.) Genetic and Metabolic Disease in Pediatrics. Butterworths International Medical Reviews; 2014. p.56-90. Available from: doi: 10.1016/ C2013-0-03993-X.

[29] Deng H, Huang X, Yuan L. Molecular genetics of the COL2A1-related disorders. Mutation Research/Reviews in Mutation Research. 2016; 768: 1-13. Available from: doi: 10.1016/j.mrrev.2016.02.003.

[30] Kuivaniemi H and Tromp G. Type III collagen (COL3A1): gene and protein structure, tissue distribution, and associated diseases. Gene. 2019; 707: 151-171. Available from: doi: 10.1016/j.gene.2019.05.003.

[31] Sadasivuni KK, Saha P, Adhikari J, Deshmukh K, Ahamed MB, Cabibihan JJ. Recent advances in mechanical properties of biopolymer composites: A review. Polymer Composites. 2020; 41(1): 32-59. Available from: doi: $10.1002 /$ pc. 25356 .

[32] Borumand M, Sibilla S. Effects of a nutritional supplement containing collagen peptides on skin elasticity, hydration and wrinkles. Journal of Medical Nutrition and Nutraceuticals. 2015; 4(1): 47-53. Available from: doi: https://www.jmnn.org/text.asp?2015/4/1/47/146161 [Accessed 15th October 2021].

[33] Zhang D, Wu X, Chen J, Lin K. The development of collagen based composite scaffolds for bone regeneration. Bioactive Materials. 2018; 3(1): 129-138. Available from: doi: 10.1016/j.bioactmat.2017.08.004.

[34] Peng H, Liu X, Wang R, Jia F, Dong L, Wang Q. Emerging nanostructured materials for musculoskeletal tissue engineering. Journal of Materials Chemistry B. 2014; 2(38): 6435-6461. Available from: doi: 10.1039/ C4TB00344F.

[35] Naffa R, Maidment C, Ahn M, Ingham B, Hinkley S, Norris G. Molecular and structural insights into skin collagen reveals several factors that influence its architecture. International Journal of Biological Macromolecules. 2019; 128: 509-520. Available from: doi: 10.1016/j.ijbiomac.2019.01.151.

[36] Shin JW, Kwon SH, Choi JY, Na JI, Huh CH, Choi HR, Park KC. Molecular mechanisms of dermal aging and antiaging approaches. International Journal of Molecular Sciences. 2019; 20(9): 2126. Available from: doi: 10.3390/ijms20092126.

[37] Aguirre-Cruz G, León-López A, Cruz-Gómez V, Jiménez-Alvarado R, Aguirre-Álvarez G. Collagen hydrolysates for skin protection: Oral administration and topical formulation. Antioxidants. 2020; 9(2): 181. Available from: doi: 10.3390/antiox9020181.

[38] Pandolfi A, Gizzi A, Vasta M. A microstructural model of cross-link interaction between collagen fibrils in the human cornea. Philosophical Transactions of the Royal Society A. 2019; 377(2144): 20180079. Available from: doi: 10.1098/rsta.2018.0079.

[39] Chen Z, You J, Liu X, Cooper S, Hodge C, Sutton G, Crook JM, Wallace GG. Biomaterials for corneal bioengineering. Biomedical Materials. 2018; 13(3): 032002. Available from: doi: 10.1088/1748-605X/aa92d2.

[40] Zhou HY, Cao Y, Wu J, Zhang WS. Role of corneal collagen fibrils in corneal disorders and related pathological conditions. International Journal of Ophthalmology. 2017; 10(5): 803. Available from: doi: 10.18240/ 
ijo.2017.05.24.

[41] Solaymani S, Nezafat NB, Ţălu Ş, Shafiekhani A, Dalouji V, Amiri A, Rezaee S, Morozov IA. Atomic force microscopy studies of enamel, inner enamel, dentin, and cementum in canine teeth. Microscopy Research and Technique. 2021; 84(6): 1098-1105. Available from: doi: 10.1002/jemt.23668.

[42] Deymier-Black AC, Almer JD, Stock SR, Dunand DC. Variability in the elastic properties of bovine dentin at multiple length scales. Journal of the Mechanical Behavior of Biomedical Materials. 2012; 5(1): 71-81. Available from: doi: 10.1016/j.jmbbm.2011.08.005.

[43] Goldberg M, Smith AJ. Cells and extracellular matrices of dentin and pulp: a biological basis for repair and tissue engineering. Critical Reviews in Oral Biology \& Medicine. 2004; 15(1): 13-27. Available from: doi: 10.1177/154411130401500103.

[44] Matsumura H, Mohri Y, Morinaga H, Fukuda M, Kurata S, Nishimura EK. Hair follicle aging is driven by transepidermal elimination of stem cells via COL17A1 proteolysis. Journal of Dermatological Science. 2017; 86(2): e53. Available from: doi: 10.1016/j.jdermsci.2017.02.156.

[45] Pauschinger M, Doerner A, Remppis A, Tannhäuser R, Kühl U, Schultheiss HP. Differential myocardial abundance of collagen type I and type III mRNA in dilated cardiomyopathy: effects of myocardial inflammation. Cardiovascular Research. 1998; 37(1): 123-129. Available from: doi: 10.1016/S0008-6363(97)00217-4.

[46] Davison-Kotler E, Marshall WS, García-Gareta E. Sources of collagen for biomaterials in skin wound healing. Bioengineering. 2019; 6(3): 56. Available from: doi: 10.3390/bioengineering6030056.

[47] Widdowson J P, Picton AJ, Vince V, Wright CJ, Mearns-Spragg A. In vivo comparison of jellyfish and bovine collagen sponges as prototype medical devices. Journal of Biomedical Materials Research Part B: Applied Biomaterials. 2018; 106(4): 1524-1533. Available from: doi: 10.1002/jbm.b.33959.

[48] Walsh G, Jefferis R. Post-translational modifications in the context of therapeutic proteins. Nature biotechnology. 2006; 24(10): 1241-1252. Available from: doi: 10.1038/nbt1252.

[49] Wolak M, Bojanowska E, Staszewska T, Piera L, Szymański J, Drobnik J. Histamine augments collagen content via $\mathrm{H} 1$ receptor stimulation in cultures of myofibroblasts taken from wound granulation tissue. Molecular and Cellular Biochemistry. 2021; 476(2): 1083-1092. Available from: doi: 10.1007/s11010-020-03974-6.

[50] Lee CH, Singla A, Lee Y. Biomedical applications of collagen. International journal of pharmaceutic. 2001; 221(12): 1-22. Available from: doi: 10.1016/S0378-5173(01)00691-3.

[51] Chak V, Kumar D, Visht S. A review on collagen based drug delivery systems. International Journal of Pharmacy Teaching \& Practices. 2013; 4(4): 811-820. Available from: https://www.iomcworld.org/articles/a-review-oncollagen-based-drug-delivery-systems.pdf [Accessed 15th October 2021].

[52] Khan R, Khan MH. Use of collagen as a biomaterial: An update. Journal of Indian Society of Periodontology. 2013; 17(4): 539-542. Available from: doi: 10.4103/0972-124X.118333.

[53] Xiong S, Gao H, Qin L, Jia Y, Gao M, Ren L. Microgrooved collagen-based corneal scaffold for promoting collective cell migration and antifibrosis. RSC Advances. 2019; 9(50): 29463-29473. Available from: doi: 10.1039/ C9RA04009A.

[54] Nakagawa T, Tagawa T. Ultrastructural study of direct bone formation induced by BMPs-collagen complex implanted into an ectopic site. Oral Diseases. 2000; 6(3): 172-179. Available from: doi: 10.1111/j.1601-0825.2000. tb00329.x.

[55] Marks MG, Doillon C, Silvert FH. Effects of fibroblasts and basic fibroblast growth factor on facilitation of dermal wound healing by type I collagen matrices. Journal of Biomedical Materials Research. 1991; 25(5): 683-696. Available from: doi: 10.1002/jbm.820250510.

[56] Patil SB, Inamdar SZ, Reddy KR, Raghu AV, Soni SK, Kulkarni RV. Novel biocompatible poly (acrylamide)grafted-dextran hydrogels: Synthesis, characterization and biomedical applications. Journal of microbiological methods. 2019; 159: 200-210. Available from: doi: 10.1016/j.mimet.2019.03.009.

[57] Patil SB, Inamdar SZ, Reddy KR, Raghu AV, Akamanchi KG, Inamadar AC, Das KK, Kulkarni RV. Functionally tailored electro-sensitive poly (acrylamide)-g-pectin copolymer hydrogel for transdermal drug delivery application: synthesis, characterization, in-vitro and ex-vivo evaluation. Drug Delivery Letters. 2020; 10(3): 185-196. Available from: doi: 10.2174/2210303110666200206114632.

[58] Patil SB, Inamdar SZ, Das KK, Akamanchi KG, Patil AV, Inamadar AC, Reddy KR, Raghu AV, Kulkarni RV. Tailor-made electrically responsive poly (acrylamide)-graft-pullulan copolymer based transdermal drug delivery systems: synthesis, characterization, in-vitro and ex-vivo evaluation. Journal of Drug Delivery Science and Technology. 2020; 56: 101525. Available from: doi: 10.1016/j.jddst.2020.101525.

[59] Uchio Y, Ochi M, Matsusaki M, Kurioka H, Katsube K. Human chondrocyte proliferation and matrix synthesis 
cultured in Atelocollagen ${ }^{\circledR}$ gel. Journal of Biomedical Materials Research: An Official Journal of The Society for Biomaterials, The Japanese Society for Biomaterials, and The Australian Society for Biomaterials and the Korean Society for Biomaterials. 2000; 50(2): 138-143. Available from: doi: 10.1002/(SICI)10974636(200005)50:2\%3C138::AID-JBM7\%3E3.0.CO;2-K.

[60] Harikrishnan P, Sivasamy A. Preparation, characterization of Electrospun Polycaprolactone-nano Zinc oxide composite scaffolds for Osteogenic applications. Nano-Structures \& Nano-Objects. 2020; 23: 100518. Available from: doi: 10.1016/j.nanoso.2020.100518.

[61] Cengiz IF, Pereira H, de Girolamo L, Cucchiarini M, Espregueira-Mendes J, Reis RL, Oliveira JM. Orthopaedic regenerative tissue engineering en route to the Holy Grail: disequilibrium between the demand and the supply in the operating room. Journal of Experimental Orthopaedics. 2018; 5(1): 1-14. Available from: doi: 10.1186/s40634018-0133-9.

[62] Zhang D, Wu X, Chen J, Lin K. The development of collagen based composite scaffolds for bone regeneration. Bioactive Materials. 2018; 3(1): 129-138. Available from: doi: 10.1016/j.bioactmat.2017.08.004.

[63] Samadikuchaksaraei A, Gholipourmalekabadi M, Erfani Ezadyar E, Azami M, Mozafari M, Johari B, Kargozar S, Jameie SB, Korourian A, Seifalian AM. Fabrication and in vivo evaluation of an osteoblast-conditioned nanohydroxyapatite/gelatin composite scaffold for bone tissue regeneration. Journal of Biomedical Materials Research Part A. 2016; 104(8): 2001-2010. Available from: doi: 10.1002/jbm.a.35731.

[64] Cai Y, Li J, Poh CK, Tan HC, San Thian E, Fuh JY, Sun J, Tay BY, Wang W. Collagen grafted 3D polycaprolactone scaffolds for enhanced cartilage regeneration. Journal of Materials Chemistry B. 2013; 1(43): 5971-5976. Available from: doi: 10.1039/C3TB20680G.

[65] Schultz GS, Chin GA, Moldawer L, Diegelmann RF. Principles of Wound Healing. In: Fitridge R, Thompson M. (eds.) Mechanisms of Vascular Disease: A Reference Book for Vascular Specialists. Adelaide, Australia: University of Adelaide Press; 2011. p.423-450. Available from: doi: 10.1017/UPO9781922064004.

[66] Xue M, Jackson CJ. Extracellular matrix reorganization during wound healing and its impact on abnormal scarring. Advances in Wound Care. 2015; 4(3): 119-136. Available from: doi: 10.1089/wound.2013.0485.

[67] Ghosal K, Thomas S, Kalarikkal N, Gnanamani A. Collagen coated electrospun polycaprolactone (PCL) with titanium dioxide ( $\mathrm{TiO}$ 2) from an environmentally benign solvent: Preliminary physico-chemical studies for skin substitute. Journal of Polymer Research. 2014; 21(5): 1-5. Available from: doi: 10.1007/s10965-014-0410-y.

[68] Ghosal K, Manakhov A, Zajíčková L, Thomas S. Structural and surface compatibility study of modified electrospun poly ( $\varepsilon$-caprolactone)(PCL) composites for skin tissue engineering. Aaps Pharmscitech. 2017; 8(1): 72-81. Available from: doi: 10.1208/s12249-016-0500-8.

[69] León-López A, Morales-Peñaloza A, Martínez-Juárez VM, Vargas-Torres A, Zeugolis DI, Aguirre-Álvarez G. Hydrolyzed collagen—sources and applications. Molecules. 2019; 24(22): 4031. Available from: doi: 10.3390/ molecules 24224031.

[70] Sun X, Yang X, Song W, Ren L. Construction and Evaluation of Collagen-Based Corneal Grafts Using Polycaprolactone To Improve Tension Stress. ACS omega. 2020; 5(1): 674-682. Available from: doi: 10.1021/ acsomega.9b03297.

[71] Chae JJ, McIntosh Ambrose W, Espinoza FA, Mulreany DG, Ng S, Takezawa T, Trexler MM, Schein OD, Chuck RS, Elisseeff JH. Regeneration of corneal epithelium utilizing a collagen vitrigel membrane in rabbit models for corneal stromal wound and limbal stem cell deficiency. Acta ophthalmologica. 2015; 93(1): e57-e66. Available from: doi: 10.1111/aos.12503.

[72] Sharma S, Srivastava D, Grover S, Sharma V. Biomaterials in tooth tissue engineering: a review. Journal of Clinical and Diagnostic Research. 2014; 8(1): 309-315. Available from: doi: 10.7860/JCDR/2014/7609.3937.

[73] Wang W, Chen M, Wu J, Wang S. Hypothermia protection effect of antifreeze peptides from pigskin collagen on freeze-dried Streptococcus thermophiles and its possible action mechanism. LWT-Food Science and Technology. 2015; 63(2): 878-885. Available from: doi: 10.1016/j.lwt.2015.04.007.

[74] Dharupaneedi SP, Anjanapura RV, Han JM, Aminabhavi TM. Functionalized graphene sheets embedded in chitosan nanocomposite membranes for ethanol and isopropanol dehydration via pervaporation. Industrial \& Engineering Chemistry Research. 2014; 53(37): 14474-14484. Available from: doi: 10.1021/ie502751h.

[75] Suhas DP, Raghu AV, Jeong HM, Aminabhavi TM. Graphene-loaded sodium alginate nanocomposite membranes with enhanced isopropanol dehydration performance via a pervaporation technique. RSC advances. 2013; 3(38): 17120-17130. Available from: doi: 10.1039/C3RA42062K.

[76] Suhas DP, Aminabhavi TM, Raghu AV. para-Toluene sulfonic acid treated clay loaded sodium alginate membranes for enhanced pervaporative dehydration of isopropanol. Applied Clay Science. 2014; 101: 419-429. Available from: 
doi: 10.1016/j.clay.2014.08.017.

[77] Ho TC, Park JS, Kim SY, Lee H, Lim JS, Kim SJ, Choi MH, Nam SY, Chun BS. Influences of Molecular Weights on Physicochemical and Biological Properties of Collagen-Alginate Scaffolds. Marine Drugs. 2021; $19(2)$ : 85. Available from: doi: 10.3390/md19020085.

[78] Yang Y, Ritchie AC, Everitt NM. Recombinant human collagen/chitosan-based soft hydrogels as biomaterials for soft tissue engineering. Materials Science and Engineering: C. 2021; 121: 111846. Available from: doi: 10.1016/ j.msec.2020.111846.

[79] Feng X, Xu P, Shen T, Zhang Y, Ye J, Gao C. Influence of pore architectures of silk fibroin/collagen composite scaffolds on the regeneration of osteochondral defects in vivo. Journal of Materials Chemistry B. 2020; 8(3): 391405. Available from: doi: 10.1039/C9TB01558B.

[80] de Castro KC, van de Graaf GMM, Marques RFC and Campos MGN. Chitosan and collagen composite for potential application as bone substitute. Research on Biomedical Engineering. 2019; 35(1): 65-70. Available from: doi: 10.1007/s42600-019-00002-5.

[81] Grand View Research. Collagen Market Size, Growth and Analysis Report. 2021. Available from: https://www. grandviewresearch.com/industry-analysis/collagen-market [Accessed 20th October 2021].

[82] Data Bridge Market Research. Asia-Pacific Marine Collagen Market - Industry Trends and Forecast to 2026. 2021. Available from: https://www.databridgemarketresearch.com/reports/global-marine-collagen-market [Accessed 20th October 2021].

[83] Rutschmann C, Baumann S, Cabalzar J, Luther KB, Hennet T. Recombinant expression of hydroxylated human collagen in Escherichia coli. Applied microbiology and biotechnology. 2014; 98(10): 4445-4455. Available from: doi: 10.1007/s00253-013-5447-z.

[84] Liu B, Lei YT, Zhang J, Hu L, Yang SL. Expression, purification and characterization of recombinant human gelatin in Pichia pastoris. Advanced Materials Research. 2011; 236-238: 2905-2912. Available from: doi: 10.4028/ www.scientific.net/AMR.236-238.2905.

[85] Hurskainen M, Ruggiero F, Hägg P, Pihlajaniemi T, Huhtala P. Recombinant human collagen XV regulates cell adhesion and migration. Journal of Biological Chemistry. 2010; 285(8): 5258-5265. Available from: doi: 10.1074/ jbc.M109.033787.

[86] Myllyharju J. Recombinant collagen trimers from insect cells and yeast. In: Even-Ram S, Artym V. (eds.) Extracellular Matrix Protocols. Humana Press; 2019. p.51-62. Available from: doi: 10.1007/978-1-59745-413-1_3.

[87] Jiang R, Tran M, Lönnerdal B. Recombinant Bovine and Human Osteopontin Generated by Chlamydomonas reinhardtii Exhibit Bioactivities Similar to Bovine Milk Osteopontin When Assessed in Mouse Pups Fed Osteopontin-Deficient Milk. Molecular Nutrition \& Food Research. 2021; 2000644. Available from: doi: 10.1002/ mnfr.202000644.

[88] Rasala BA, Muto M, Lee PA, Jager M, Cardoso RM, Behnke CA, Kirk P, Hokanson CA, Crea R, Mendez M, Mayfield SP. Production of therapeutic proteins in algae, analysis of expression of seven human proteins in the chloroplast of Chlamydomonas reinhardtii. Plant biotechnology journal. 2010; 8(6): 719-733. Available from: doi: 10.1111/j.1467-7652.2010.00503.x. 